\title{
Experiment teaching design of high-power smart LED driver based on Arduino
}

\author{
Yingming Gao ${ }^{1}$, Weidong Kuang ${ }^{2}$ \\ \{ gyming@dlpu.edu.cn'1781894587@qq.com²
}

School of information science and engineering, Dalian Polytechnic University, Dalian 116034, China

\begin{abstract}
For the comprehensive experimental course of light source and lighting specialty, the teaching system of high-power intelligent LED driver is developed, which is composed of Arduino board and high-power LED extended circuit board. The expansion board includes an indicator unit, an input unit and a high-power LED drive unit. The process of determining the key components of the drive unit is given in detail. The expansion board can drive 1 2 1W high-power LED within the system working voltage range of $8 \sim 12 \mathrm{~V}$, with stable output current and $88 \%$ peak efficiency. The relation curve between voltage difference and efficiency is given. For different loads, the efficiency is different even in the coincidence interval of pressure difference, which indicates that efficiency is not only related to pressure difference, But also needs to consider the load the voltage difference caused by debugging to achieve high efficiency. Experimental design is beneficial to enhance students' perceptual knowledge of high-power ledsdriver and enhance their design ability.
\end{abstract}

Keywords:Arduino,HV9910B,smart LED driver,Experimental teaching system

\section{The introduction}

Arduino, as a popular open source hardware platform, has been paid attention to by many universities. Arduino is very popular in European and American universities as a basic technology for teaching and research ${ }^{[1]}$. Many colleges and universities in China have carried out teaching reform and curriculum construction based on Arduino, so as to achieve teaching goals and improve students' innovation ability.Based on Arduino platform, Dalian University of Technology designed the basic experimental course of The Internet of Things, which 
enables students to quickly understand the hierarchical structure of the Internet of Things and cultivate their development and innovation abilities ${ }^{[2]}$. The teaching reform of Arduino-based electronics courses in USTC has stimulated students' interest in learning and promoted the cultivation of students' comprehensive quality ${ }^{[3]}$. Based on the existing teaching experience and practical teaching, Shanghai University proposed a new electronic practice teaching scheme based on Arduino open source hardware platform ${ }^{[4]}$. Shanghai Normal University offers Arduino as a professional elective course for first-year students, which cultivates students' professional interest and innovation ability ${ }^{[5]}$. By introducing Arduino into the teaching reform of electronic practical training and innovative practice, Shanghai Institute of Power inspires and improves the innovation ability of students, which is of reference significance for colleges and universities to carry out electronic practical training and innovative practical teaching reform ${ }^{[6]}$.

Arduino's original goal was to give art students an easy to use microcontroller to help them design ${ }^{[7]}$. Its INTEGRATED development environment is simple and friendly. The initial state of the hardware is set by functions rather than by various registers. It is not necessary to understand the working principle of the single chip microcomputer.With objects defined by reusable class libraries, a few lines of code can achieve the required functionality, greatly improving programming efficiency.Arduino's ease of use makes it suitable for cultivating students' innovation ability. Arduino can be used to quickly build prototype systems like "building blocks", so as to avoid spending too much time and energy on basic functions and focus on innovative work of method verification or functional experience.This experimental teaching system combines Arduino with LED drive technology to quickly build an intelligent lighting prototype system with sensing and network functions.Through this system, students' innovation ability of intelligent lighting is cultivated, and their verification and experience of intelligent lighting effect and even research on basic methods of lighting control are carried out, laying a foundation for their future career in intelligent lighting industry.

\section{Smart drive design}

The chip-level intelligent LED driver has dimming function and can communicate with the microcontroller through SPI, I2C, single-bus and other serial communication interfaces ${ }^{[8]}$. This driver has no computing power and can only get the dimming information from the single chip microcomputer through serial interface. Since the Arduino itself provides a variety of serial interfaces, this intelligent driver can be simulated by combining the Arduino and LED 
driver, as shown in Figure 1 in the form of "Arduino+ high-power LED Drive extension board".It has a stronger ability to expand, the serial interface if connected to the network communication module and sensor module, easy to be extended to the intelligent lighting system.

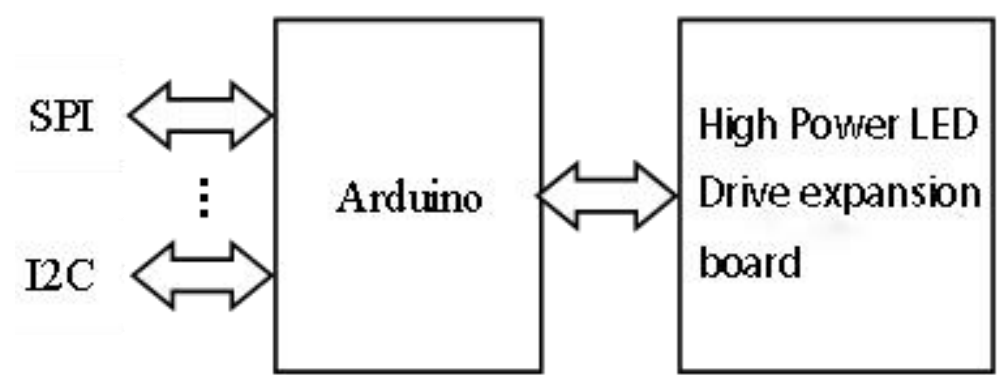

Fig. 1. Structure of intelligent LED driver

\subsection{Expansion board design of high-power LED driver}

We used Arduino $\mathrm{UNO}^{[9]}$ As a processor, a high-power LED drive extension board is developed to realize the structure of the intelligent driver.The expansion board includes key input unit, LED indicator unit and high-power LED drive unit based on constant current driver HV9910B.The key is used to adjust the duty ratio of PWM dimmer signal.The LED indicator unit consists of 3 straw hats encapsulated LEDS, and displays the duty ratio of the current PWM signal with a combination of "light/dark" state.

Table 1. Pins of Arduino UNO for the extension board connection

\begin{tabular}{lll}
\hline Arduino pin types & The name of the pin & Directions for use \\
\hline The power supply pins & VIN & Power supply 7 12V for Arduino \\
The power supply pins & GND & The reference to \\
Digital pins & Pin 3 & PWM signal output for dimming \\
Digital pins & Pins 5,6 & Input pins are used to connect keys \\
Digital pins & Pins $8,9,10$ & Output pins are used for low power \\
& & leds \\
\hline
\end{tabular}


The Arduino UNO pins used in the extension board are shown in Table 1. They insert the pins into the slot of the Arduino board, so that the extension board can be placed above the Arduino in the installation form shown in Figure 2.Arduino UNO provides three types of pins, namely, the power pin, the analog input pin, and the digital pin. Among them, the digital pin is multiplexed with the PWM output pin and the serial communication pin.Dc power supply is adopted in the system. The positive pole is connected to the Arduino VIN slot through an extension board, and the negative pole is connected to the Arduino GND slot through another inserting pin. The input voltage range of Arduino UNO is 7 12V, and the operating voltage range of the drive unit HV9910B is $8 \sim 450 \mathrm{~V}^{[10][11]}$. Therefore, the input voltage range of smart drivers is $8 \sim 12 \mathrm{~V}$.Digital pins $8 \sim 10$ are used to drive three low-power leds in the indicating unit. "bright" and "dark" respectively represent binary numbers 1 and 0 . Their "light/dark" combination can indicate eight PWM signals with different duty ratio.

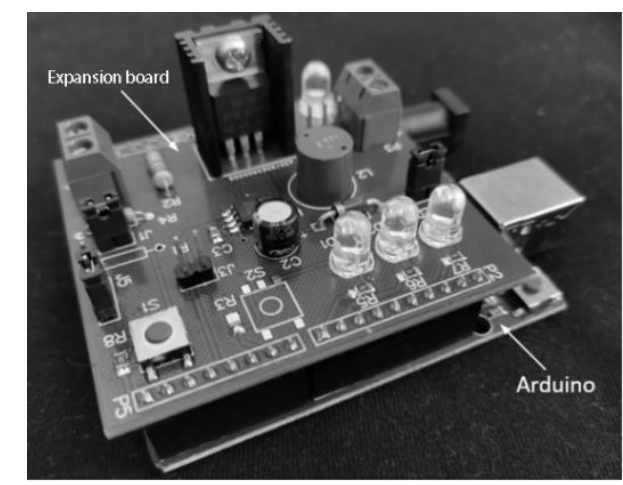

Figure. 2. The connection form between the extension board and Arduino

Fig. 3 is the high-power LED drive unit designed by BUCK.HV9910B can output two kinds of PWM switch signals with constant cycle and constant low level time to drive the step-down converter circuit.As a buck converter and operating in continuous current mode, when the output voltage UouTGreater than the input voltage $\mathrm{U}_{\mathrm{IN}} \mathrm{When} 50 \%$, that is, when the duty ratio of the switching signal is greater than 0.5 , it is advisable to use the switching signal with constant low level time to avoid sub-harmonic oscillation ${ }^{[12]}$. The switch signal may be transmitted by oscillating resistance $\mathrm{R}_{\mathrm{T}}$ Settings, $\mathrm{R}_{\mathrm{T}}$ One end is connected to pin 8 , the other end is earthed and the other end is connected to pin 4, which is a switch signal with constant low-level time ${ }^{[7]}$. By introducing jumper wire into the circuit (P3 in FIG. 3), the system can switch between these two switch signals, ensuring the stability of driving multiple high-power leds. 


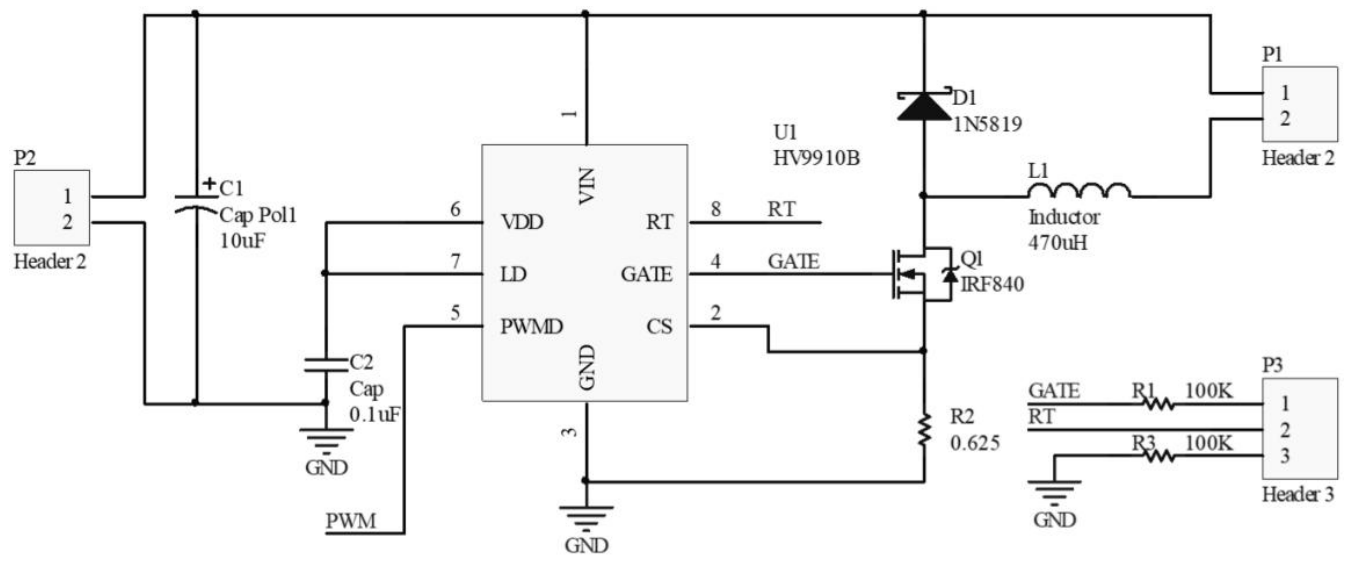

Fig. 3.High power LED drive circuit design

\subsection{Determination of key components}

The design indicator of the expansion board is: input voltage $\mathrm{U}_{\mathrm{IN}}$ When the range is $8 \sim 12 \mathrm{~V}$, the

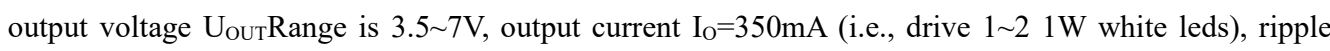
current is $30 \%$. Since the ratio between the maximum output voltage $7 \mathrm{~V}$ and the minimum input voltage $8 \mathrm{~V}$ is 0.9 and greater than 0.5 , the low-level time-constant PWM signal is adopted.The components to be determined are current detector resistor R2, oscillation resistor R1 or R3 (determined by jumper), power inductor L1 in the switch converter circuit, field effect transistor Q1 and diode D1, as shown in Fig. 3.

$$
\begin{gathered}
\mathrm{R}_{\mathrm{CS}}=\frac{0.25 \mathrm{~V}}{1.15 \cdot \mathrm{I}_{\mathrm{LED}}(\mathrm{A})} \\
\mathrm{R}_{\mathrm{T}}(\mathrm{K} \Omega)=25 \cdot \mathrm{t}_{\mathrm{OSC}}(\mu \mathrm{s})-22
\end{gathered}
$$

Equation (1) calculates the galvanometer resistance.HV9910B belongs to the peak current controller, and the current detection resistance is determined by the peak current.As the ripple current is $30 \%$, it is the peak current according to the relationship between average current and ripple current. $I_{O}=$ $I_{L E D} 1.15 \cdot I_{L E D}$ Substitute 0.35 a into equation (1), and you get $\mathrm{R} I_{L E D C S} \mathrm{R} 2==0.62 \Omega$.

Equation (2) is used to calculate the oscillation resistance.If THE PWM signal is periodic, then in 
the formula is the period of the signal. $t_{O S C}$ If PWM signal is low level time constant, then in the formula is low level time. $t_{O S C}$ For low-voltage input, a low level time of $5 \mathrm{~s}$, corresponding to $\mathrm{R}$, is recommended when using a PWM signal with a constant low level time $\mathrm{T} \Omega=\mathrm{R} 1=100 \mathrm{k}$.

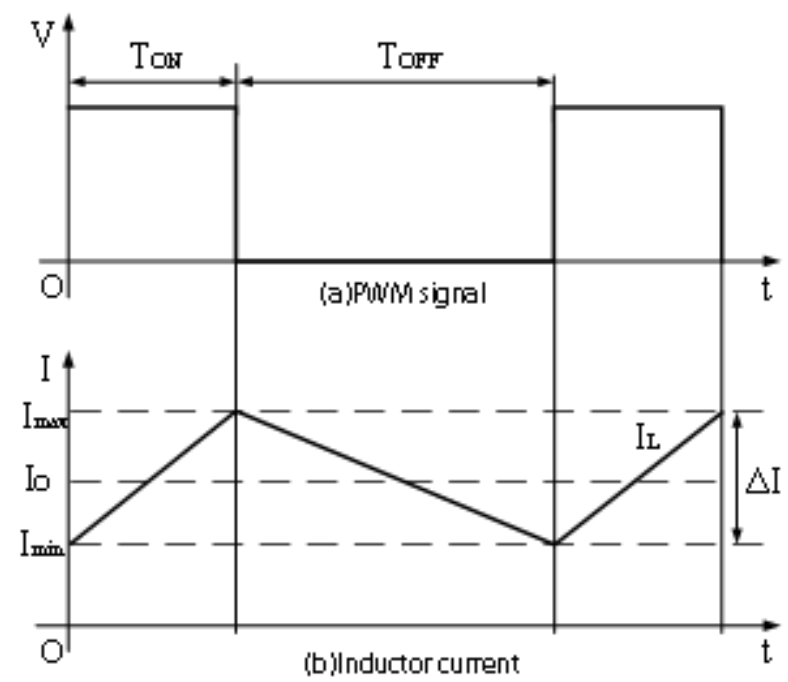

Fig. 5. Relationship between step-down circuit PWM signal and inductive current

$$
L=\frac{U_{L} \cdot \Delta t}{\Delta I}
$$

Formula (3) calculates the power inductance, where is the inductance voltage, is the increment of the inductance current, and is the corresponding time increment. $U_{L} \Delta I \Delta t \Delta I$ In the PWM signal TofF It is more convenient to calculate inductance when period $\mathrm{Q}$ is cut off. At this time, field effect tube $\mathrm{Q}$ is cut off and diode D is switched on. Fig.6 Circuit (a) is equivalent to circuit (c) and inductance voltage $\mathrm{U}_{\mathrm{L}} \mathrm{Is}$ equal to the output voltage Uour.It can be seen from Fig. 5 that the decrease of the inductance current during the period is the ripple current. $\Delta t=T_{O F F} \Delta I$ To drive two $1 \mathrm{~W}$ leds, set $\mathrm{U}_{\mathrm{L}}=\mathrm{U}_{\text {ouT }}$ If $\mathrm{A}$ is substituted into equation (3), the power inductance $\mathrm{L}=333 \mathrm{H}$ can be considered as the minimum theoretical inductance that meets the requirements, and the ripple current can be reduced by using $\mathrm{A}$ larger inductance than it. $\Delta t=T_{\text {OFF }}=0.5 \mu s \Delta I=0.35 \times 0.3=0.1$ 


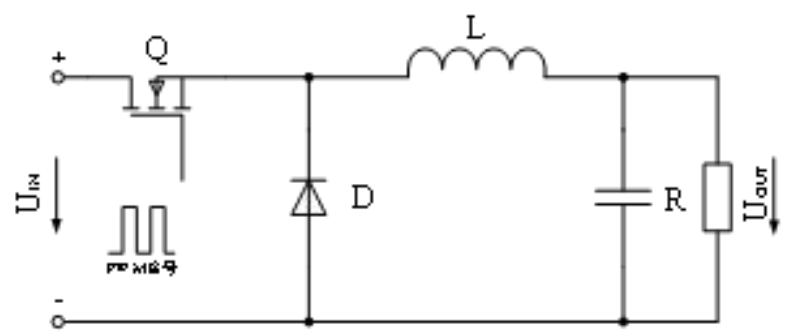

(a) Buck converter ciruit

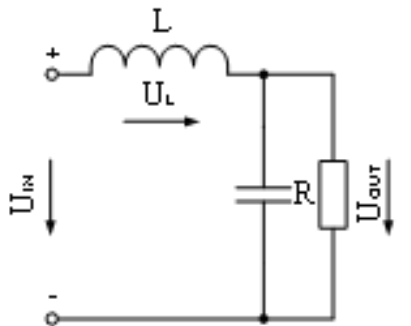

(b) Conductingcircuit

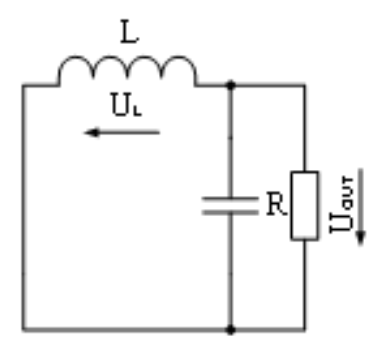

(c)Cutoff circuit

Fig. 6. Topological structure and state transition of step-down circuit

The system uses field effect tube IRF840 and Schottky diode 1N5819 as switching elements.In addition to the voltage, current bearing capacity to consider, their switching speed and PWM signal frequency match, otherwise the circuit can not work normally. As shown in Fig. 6, PWM signal makes field effect tube Q in step-down circuit (A) switch between on and off, and diode D switch between off and on, thus making circuit (a) cycle switch between circuit (b) and circuit (c) to realize voltage transformation function.Ideally, the switch is instantaneous and fully synchronized with THE PWM signal, as shown in Fig.7 (b) Curve 1.However, under the influence of junction capacitance, the voltage at both ends of PN junction cannot mutate, and the switching state conversion of devices always lags behind the change of PWM signal[13]. Only when the device's switching time $T_{\text {on }}$ And $t_{\text {off }}$ The state conversion can be completed only when the holding time of PWM signal is less than that of PWM signal, as shown in Fig.7 (b) Curve 2.If the PWM signal frequency is too fast, its holding time is shorter than the switching time of the device, as shown in Fig. 7(b) curve 3, resulting in the device never being able to transfer state and the step-down switch circuit is unable to perform voltage transformation function. 


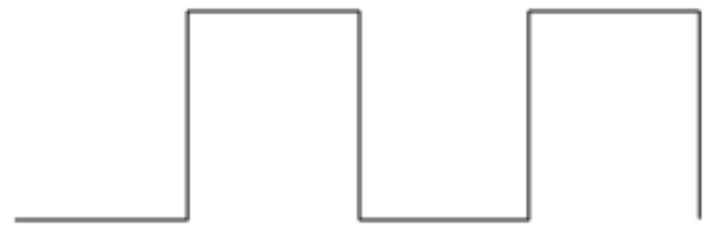

(a) Pinhy signal

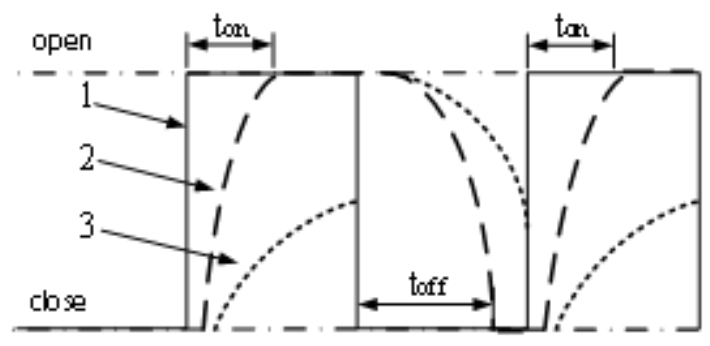

(b) Switch characteristics

Fig. 7. Relationship between PWM signal and device switching time

\section{System perfor test}

\subsection{Index Test}

Efficiency is equal to the ratio of output power to input power. For dc power supply, power is equal to the product of voltage and current. The input voltage and current are measured respectively. After the output voltage and current, the input power and output power are calculated to obtain the efficiency. 


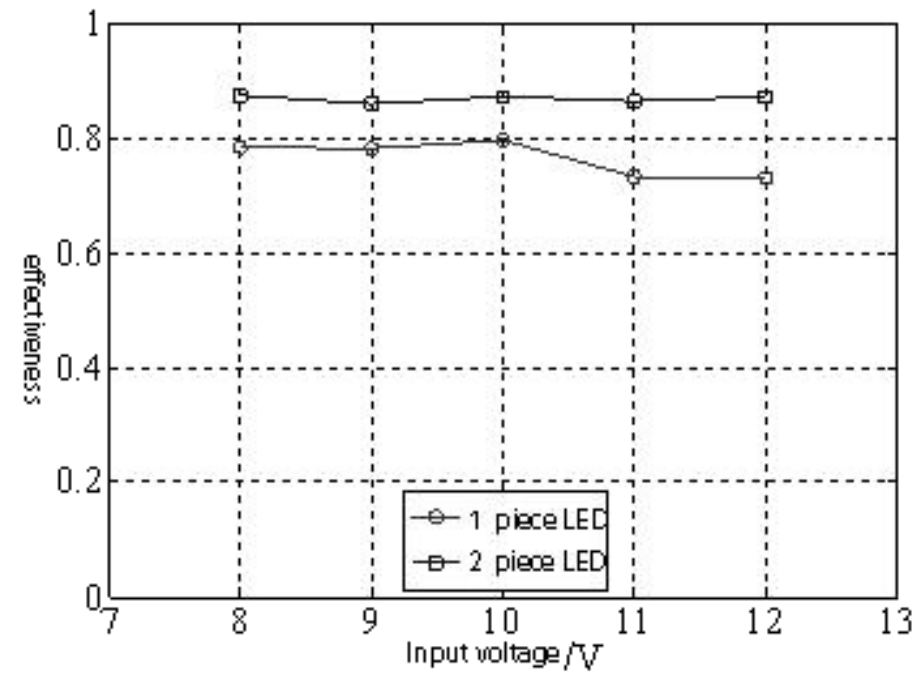

Fig. 8. Relation curve between input voltage and efficiency

As shown in Fig. 8: The input voltage of the expansion plate is within the range of $8 \sim 12 \mathrm{~V}$, and the maximum efficiency of driving $1 \mathrm{lW}$ high-power LED and $21 \mathrm{~W}$ high-power LED is measured as $80 \%$ and $88 \%$ respectively. The efficiency of $21 \mathrm{~W}$ high-power leds driven by expansion board is higher than that of $1 \mathrm{~W}$ high-power leds driven by expansion board.

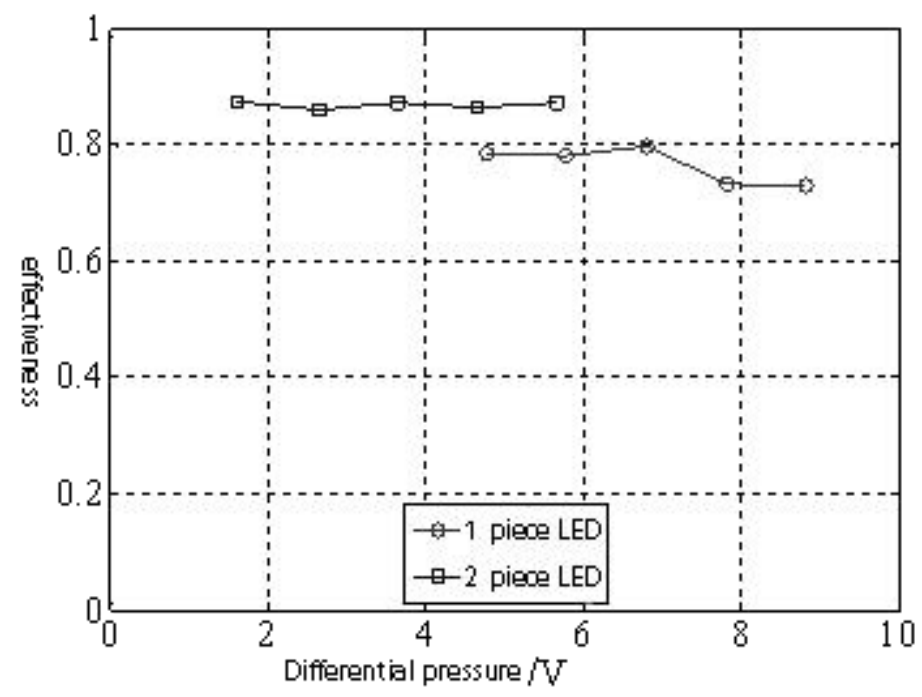

Fig. 9. Relation curve between pressure difference and efficiency 
It can be seen from Figure 9 that when the input voltage is $8-12 \mathrm{~V}$, the efficiency is relatively stable when driving 2 leds with the increase of the difference between input voltage and output voltage, while when driving $1 \mathrm{LED}$, the efficiency tends to decline with the increase of the pressure difference.But the pressure difference and efficiency are not one to one correspondence relation, for the above two kinds of loads, in the overlap area of the pressure difference, the efficiency has the more obvious difference. It shows that the efficiency is related to the pressure difference and the load, and the load and the pressure difference caused by the load should be considered comprehensively to obtain the high efficiency.

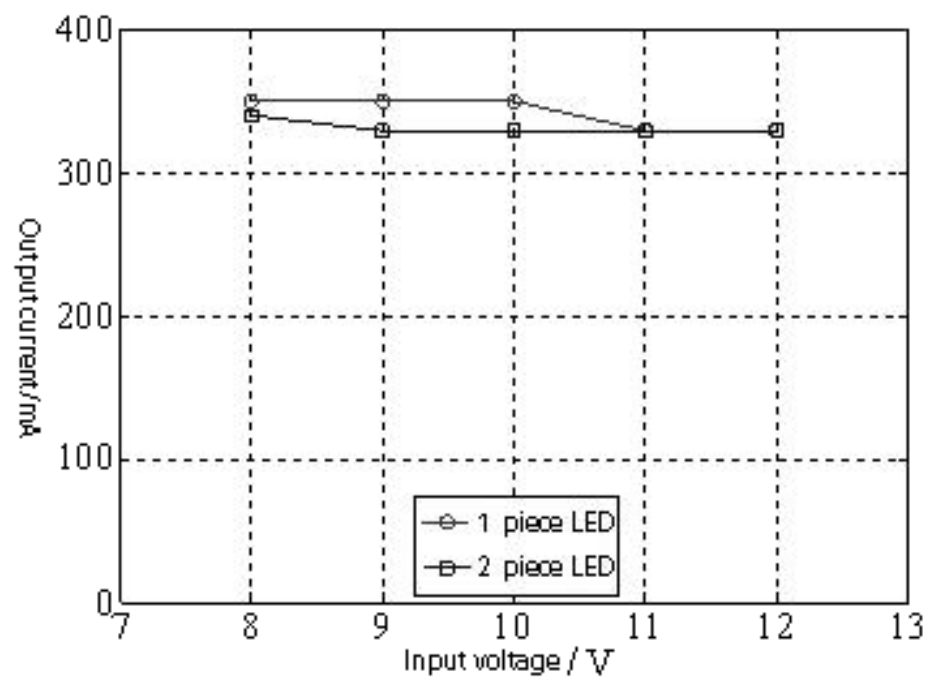

Fig. 10. Relationship between input voltage and output current

Fig. 10 shows the corresponding relationship between the output current and the input voltage when the input voltage of the expansion plate is $8 \sim 12 \mathrm{~V}$ and 1 LED and 2 LED are respectively driven.As the output voltage changes, the output current is relatively stable, with a maximum of $345 \mathrm{~mA}$ and a minimum of $327 \mathrm{~mA}$, slightly smaller than the target output current of $350 \mathrm{~mA}$.

\subsection{Signal testing}

Fig. 11 shows the gate voltage waveform of the field effect tube (the switching signal output by HV9910B) and the corresponding diode positive voltage waveform at the input voltage of $9 \mathrm{~V}$ and $12 \mathrm{~V}$. Channel 1 is the PWM signal waveform and channel 2 is the diode positive voltage waveform.According 
to the measurement results, for low level PWM signal with constant time, its period decreases with the increase of input voltage under the condition of certain load. This is consistent with the effect of the output voltage/input voltage on duty cycle of the step-down switch converter circuit. The field-effect tube grid voltage waveform is complementary to the diode positive voltage waveform. The maximum voltage of the diode positive electrode varies with the input voltage and is the same as the input voltage. The output switching signal of HV9910B does not change with the input voltage.
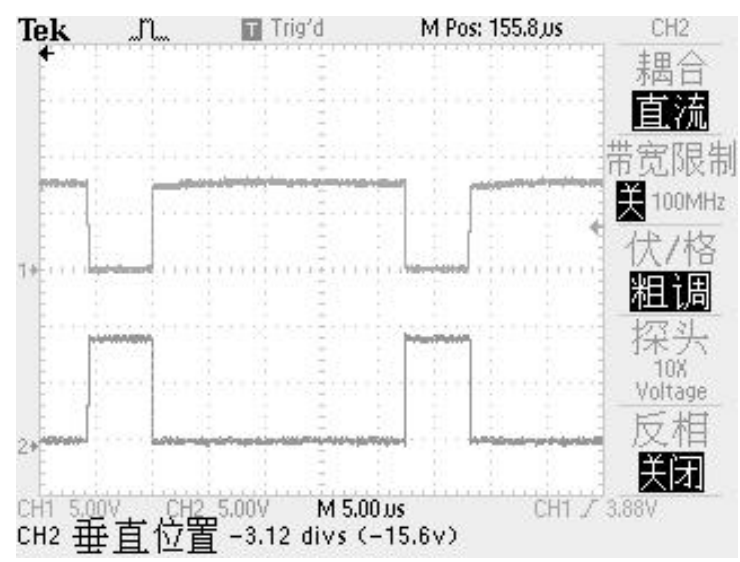

(a) Waveform of input voltage $9 \mathrm{~V}$

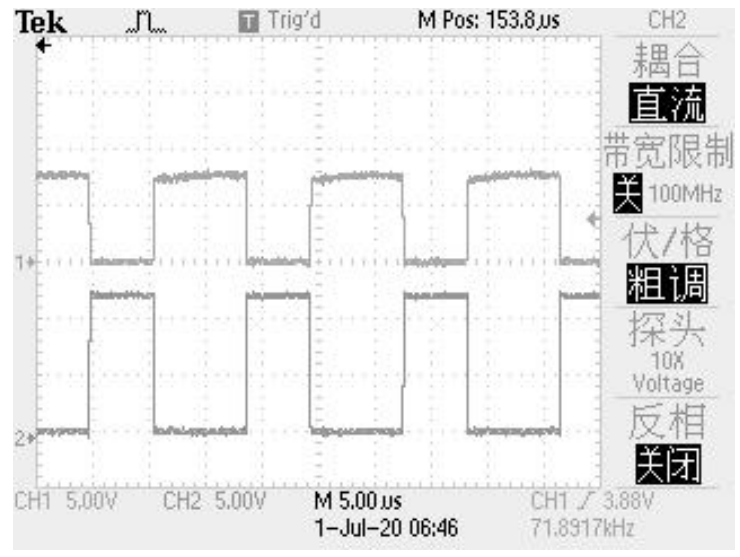

(b) Waveform with input voltage of $12 \mathrm{~V}$

Fig. 11.Voltage waveform of switching signal and diode positive pole

Fig. 12 shows the corresponding relationship between the switching signal output from HV9910B and the dimming signal input from the pin of PWMD (duty ratio is 10\%). Channel 1 is the switching signal and channel 2 is the dimming signal.In dimming, the switching signal output from HV9910B is 
not output until the dimming signal is at high voltage, but not at low voltage. The actual switching signal output from HV9910B is the result of logic "and" operation between the dimming signal and the continuous switching signal.

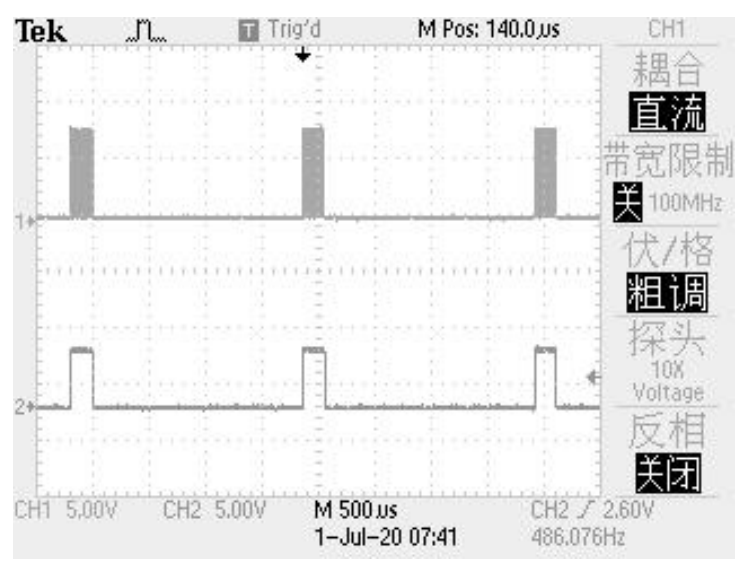

(a) The overall characteristics of the two signals

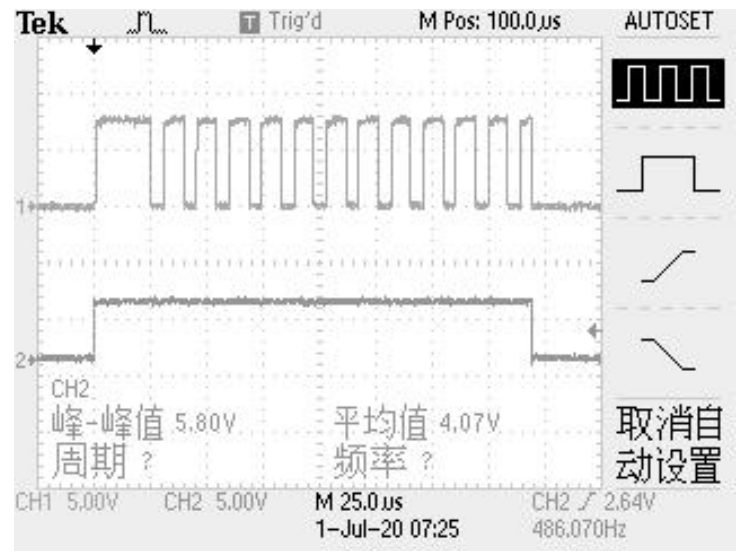

(b) Local characteristics of two signals

Fig. 12.Waveform of switching signal and dimming signal

\section{Experimental teaching content design}

This experimental teaching system can meet the needs of comprehensive experiment of light source and lighting specialty. The Arduino application can complete PWM signal output and serial communication functions by calling relevant functions. Compared with the traditional register operation mode, it saves a lot of repetitive basic code writing, and quickly builds intelligent lighting system to 
verify and study the lighting control strategy.The contents that can be offered in experimental teaching include:

(1) High-power LED dimming experiment.The program changes the duty ratio of dimming signal output by Arduino digital pin 3 by pressing buttons to achieve dimming of high-power LED.The duty ratio of dimmer signal starts from 0 . As the key is pressed down each time, the cycle increases the duty ratio to $100 \%$ in accordance with Table 2 and then returns to 0 . At the same time, the "light/dark" combination of three low-power leds on the expansion board is changed accordingly.Measure the working current of high-power LED under different duty ratio, draw the working current curve of duty ratio and working current, and intuitively understand the relationship between LED working current and dimming duty ratio.

Table 2. Is the corresponding relationship between duty ratio and LED on-off combination

\begin{tabular}{ccccl}
\hline LED2 & LED1 & LED0 & $\begin{array}{c}\text { The serial } \\
\text { number }\end{array}$ & Duty ratio \\
\hline $0 /$ dark & $0 /$ dark & $0 /$ dark & 0 & 0 \\
$0 /$ dark & $0 /$ dark & $1 /$ bright & 1 & $5 \%$ \\
$0 /$ dark & $1 /$ bright & $0 /$ dark & 2 & $10 \%$ \\
$0 /$ dark & $1 /$ bright & $1 /$ bright & 3 & $20 \%$ \\
$1 /$ bright & $0 /$ dark & $0 /$ dark & 4 & $40 \%$ \\
$1 /$ bright & $0 /$ dark & $1 /$ bright & 5 & $60 \%$ \\
$1 /$ bright & $1 /$ bright & $0 /$ dark & 6 & $80 \%$ \\
$1 /$ bright & $1 /$ bright & $1 /$ bright & 7 & $100 \%$ \\
\hline
\end{tabular}

(2) When not dimming, use oscilloscope to observe switch signals output by GATE pins of HV9910, record signal cycle, holding time of high level and low level, and compare with theoretical values.During dimming, use oscilloscope to observe the switch signal output by GATE pin, and record the change of output signal with dimming signal. Explain the logic operation relation between switching signal in dimming, switching signal in non-dimming and dimming signal.

(3) Illumination control experiment. The GY-30 illumination sensor module of I2C interface and the intelligent LED driver constitute the intelligent lighting control system. With the ON/OFF control strategy, the program realizes the illumination control of the working surface, that is, when the illumination of the day is lower than the threshold, the light is turned ON for illumination, and when the daylight is higher than the threshold, the light is turned OFF for energy saving. 


\section{Conclusion}

The experimental teaching system of high-power intelligent LED drive developed in this paper can be used in the teaching of comprehensive experimental courses of light source and lighting specialty, to help students deeply understand the working principle of LED drive, enhance perceptual knowledge, and lay a foundation for future related work. The experimental design combines Arduino technology with lighting control technology, which reduces the difficulty of programming and enables students to focus more on experimental content related to system performance test and illumination control.

\section{References}

[1] Shi Zhixiong. Application exploration of Arduino in Engineering Teaching in University [J].Journal of Xichang University, 2012, 26(4):50-54.

[2] Liu Wenjie, Zhu Ming, Tan Zhenquan. Arduino-based Temperature Control Experiment Design for the Internet of Things [J].Experimental Technology and Management, 2017, 34(1), 150-152.

[3] Wang Fan, Zhou Wenhui, Liu Baojun, et al. Teaching Reform of Electronic Design Practice Based on Arduino [J].Modern Computers, 2018, (35), 81-85.

[4] Yuan Li. Preliminary Exploration of Electronic Internship Education Reform based on open source hardware [J]. Education \& Teaching Forum, 2013, (22), 39-42.

[5] Zhang Chongming, Ye Hong, Ni Jifeng, et al. Teaching Practice of Arduino Elective course in the first year of undergraduate [J].Experimental Technology and Management, 2018, 35(3), 169-171,194.

[6] Tang Min, Jin Yiming. Preliminary Exploration on the Introduction of open source hardware into Electronic Training and Innovation Practice [J].Guide to Knowledge, 2016, 43(2), 75-76.

[7] Cui Yiwen. How did gizmodo invented by several art teachers 10 years ago give birth to today's intelligent hardware industry?[EB/OL]. [2015-08-03]. http://www.qdaily.com/articles/12926.html? source $=$ feed.

[8] Sha Zhanyou, Yu Guoqing. Typical Application of Intelligent LED Driver [J].Power Supply Technology Applications, 2011, 14(5): 56-60.

[9] Chen Luzhou. Arduino Programming Foundation (Version 2) [M].Beijing: Beijing University of Aeronautics and Astronautics Press, 2015.

Huang Jianping, SHEN Hanxin. Design and Research of LED Step-down Drive Circuit based on HV9910B [J].Modern Electronic Technology, 2014, (19): 139-142

[11] Microchip.HV9910B chip data [EB/OL]. [2014/03-09]. Http//www.supertex.com.

[12] Steve Winder. Power Supplies for LED Driving[M]. United States of America: Elsevier Inc., 2008. 
[13] Yan Shi, WANG Hong. Foundation of Digital Electronic Technology (the sixth Edition) [M].Beijing: Higher Education Press, 2016. 